\title{
Change in the Dominant Side of Chewing as a Serious Factor for Adjusting the Prophylaxis Strategy for Implant-Supported Fixed Dental Prosthesis of Bounded Lateral Defects
}

\author{
Angelina O. Zekiy ${ }^{1}$ Evgenii A. Bogatov² Igor A. Voronov³ Martiros S. Sarkisyan ${ }^{3}$ Ernest Llaka ${ }^{3}$
}

${ }^{1}$ Department of Prosthetic Dentistry, I.M. Sechenov First Moscow State Medical University, Moscow, Russian Federation

2Department of Prosthetic Dentistry, Institute of Dentistry named after E.V. Borovsky, I.M. Sechenov First Moscow State Medical University (Sechenov University), Moscow, Russia

${ }^{3}$ Department of Prosthetic Dentistry, PFUR Medical Institute, RUDN University, Moscow, Russia

Eur J Dent:2021;5:54-62

\begin{abstract}
Address for correspondence Angelina O. Zekiy, Doctor of Sciences (Medicine), Department of Prosthetic Dentistry, I.M. Sechenov First Moscow State Medical University, Trubetskaya Street, 8, Bd. 2, 119991, Moscow, Russian Federation (e-mail: angelinazekiy@yandex.ru).
\end{abstract}

\section{Abstract}

Keywords

- dental implantation

- osseointegration

- peri-implantitis

- partial loss of teeth

- chewing function

- gnathodynamometry

- electromyography

- visual analogue scale

- adaptation to dentures
Objective The main purpose of this article is to study the effect of a change in the dominant side of chewing after prosthetics with fixed structures on implants on the main indicators of osseointegration, adaptation to dentures, and the clinical dental status of patients.

Materials and Methods In a clinical trial, an analysis was made of the adaptation of 64 patients to intraosseous implant-supported fixed dentures and 56 apparently healthy volunteers. The examination complex included determination of the functionally dominant side of chewing, gnathodynamometry and electromyography indicators of masticatory muscles, and radiological osseointegration criteria. The overall treatment outcomes were evaluated using a visual analogue scale and an objective medical questionnaire, "Prognosis of Adaptation to Orthopedic Structures."

Results Patients were divided into two subgroups: with a change in the dominant side of chewing after completion of orthopaedic treatment (40 cases) and without a change in the dominant side of chewing (24 cases). In the second subgroup of patients, in contrast to the first subgroup, relatively better indicators of gnathodynamometer and electromyography were observed. So, in the first group, gnathodynamometry indicators on the dominant side were $255.7 \mathrm{~N}$ and in the second group $225 \mathrm{~N}$ after 9 to 12 months. Electromyography indices amounted to $(198.5 \mu \mathrm{V}$ s) to $(166.3 \mu \mathrm{V} \mathrm{s})$ after 9 to 12 months. Bone density remained at the required level, and overall treatment outcomes were higher. Namely, the compact plate of the alveolar ridge was preserved, and the condition of the bone tissue around the implants testified to stable osseointegration. The participation of surface masticatory muscles in adaptation of patients to intraosseous implant-supported fixed orthopaedic structures and the necessity and importance of changing the dominant chewing side for the general outcomes of orthopaedic treatment have been discussed.
DOI https://doi.org/ 10.1055/s-0040-1715551 ISSN 1305-7456. (c) 2020. European Journal of Dentistry.

This is an open access article published by Thieme under the terms of the Creative Commons Attribution-NonDerivative-NonCommercial-License, permitting copying and reproduction so long as the original work is given appropriate credit. Contents may not be used for commercial purposes, or adapted, remixed, transformed or built upon. (https://creativecommons.org/licenses/by-nc-nd/4.0/)

Thieme Medical and Scientific Publishers Pvt. Ltd., A-12, 2nd Floor, Sector 2, Noida-201301 UP, India 
Conclusions It has been established that a change in the functionally dominant chewing side is accompanied by relatively unstable indicators of chewing function, which is combined with increased loads on the installed prostheses during 3 to 6 months of adaptation. This must be taken into account when planning an individual patient adaptation complex for dental orthopaedic structures.

\section{Introduction}

Dental implantation is currently one of the dynamically developing fields of clinical dentistry. The manufacturing of intraosseous (dental) implant-supported fixed orthopaedic structures for the restoration of bounded dentition defects claims to be the "gold standard" in modern orthopaedic dentistry. Up to 2 million implants are installed annually in the world; the positive results of such prosthetics are summarized in several large retrospective studies..$^{1-3}$

It should be noted that the effectiveness ( 95-96\%) of dental implantation is evaluated mainly based on the preserved osseointegration, the integrity of the mounted structure, and questionnaires for quality of life. ${ }^{4-6}$ Thus, Jang et $\mathrm{al}^{7}$ showed on the example of a large sample of patients $(n=6385)$ examined from 2000 to 2009 that the cumulative survival rate of titanium dental implants was $96.3 \%$.

Naturally, osseointegration, which ensures the formation of a strong bond between the implant and the recipient's osseous tissue, is the basis for the reconstruction of the three-dimensional (3D) dentin architectonics; therefore, it is recognized as the main indicator of the success of dental implantation in the dynamics of the use of orthopaedic structures. ${ }^{8-10}$ Recently, various modifications of implant surface that lead to the nanorelief formation have been used to accelerate the formation and enhance the bond strength between the bone and implants. ${ }^{11-14}$

Since currently the quality of the implants and the technique of their installation have reached the optimum level, late complications, reducing the time limits of functioning of prostheses and implants, remain the only serious problem. Their causes are mainly associated with microtraumas during the orthopaedic structure functioning (inaccurate calculation of biomechanics plays a role here) and the impact of pathogenic microflora (microbial associations that colonize tissues and surfaces nearby the implant and in its internal interface). ${ }^{15-17}$ They negatively affect osseointegration; as a result, it is precisely its insufficiency that dominates among the causes of unsatisfactory outcomes of this prosthetic option., ${ }^{2,18,19}$

In connection with the above, it seems relevant to consider the influence of such factors that, outside the action of the infectious-inflammatory ones, can impose a negative effect on the stability of dental implants. The clinical task is to achieve almost complete immobility of the "tissue-implant" bond in the shortest possible time limits and to provide no traumatic effects and chewing overloads during operation of fixed orthopaedic structures. ${ }^{20-23}$
Chewing is one of the most important elements of the digestive function; it is characterized by complicated motor-sensory activity, which consists of rhythmic motor acts aimed at size reduction, food grinding, and moisturizing, which should lead to the formation of a bolus that can be swallowed. ${ }^{24,25}$

The functional significance of occlusal disorders for the masticatory system has been extensively studied, primarily because of the idea that they may have an undesirable effect on the dentofacial system. ${ }^{26}$ Various electrophysiological and video-fixing techniques have been proposed for the dynamic study of the chewing function. ${ }^{27-29}$

The restoration of occlusal surfaces, by definition, is accompanied by the restructuring of the chewing link of the dentition. In general, addiction to dentures can take from several weeks to 3 to 4 months; afterward, a stable type of chewing is usually formed, and the situation in the oral cavity stabilizes, usually no less than for 3 to 5 years. ${ }^{30}$ When restoring lost teeth with intraosseous implantsupported dentures, a functioning area of the chewing apparatus appears with new loads that extend directly to the osseous tissue, bypassing the reflex areas of periodontal tissue. This is inevitably accompanied by intensification of osteolysis processes, which in turn can exacerbate overload of supporting teeth. In case of a change in the position of the lower jaw and the height of the lower third of the face, new conditions are created for the activity of the masticatory muscles and the temporomandibular joint. ${ }^{31}$ New occlusal relationships change the perception and transfer of chewing pressure on the underlying tissues, as a result, the nature of the chewing movements of the lower jaw changes. Often this may even require a change in the dominant chewing side. ${ }^{32}$

The dentition defects arising because of tooth extraction and their deformation lead to the formation of persistent habitual occlusion, sometimes not coinciding with the predominant side of chewing. This creates an adverse effect on the dentofacial system, which leads to complications. ${ }^{33}$ In dental practice, there are many cases confirming changes in the chewing surface of teeth and dentitions on the dominant side of chewing and the need to study it when prosthetics are on dental implants. ${ }^{34}$ There is a lack of stability information on the predominant dominant side of chewing in the norm and in the absence of teeth and other pathological conditions. The nature of the occurrence of a change in the dominant side of chewing and its stability after the completion of orthopaedic treatment with the use of designs based on dental implants has not been studied. ${ }^{35}$ 
The purpose of the research was to study the effect of a change in the dominant side of chewing after prosthetics with fixed structures on implants on the main indicators of osseointegration, adaptation to dentures, and the clinical dental status of patients. In the absence of proper attention to this problem, distant moistening of prosthetics on dental implants may occur, such as temporomandibular joint dysfunction, progressive bone loss, gum recession, and inflammatory complications, which in turn can lead to the loss of a dental implant.

\section{Materials and Methods}

\section{Organization of Clinical Groups}

In this study, we observed the dynamics of orthopaedic treatment and the subsequent period of adaptation (rehabilitation) of 64 people aged 22 to 67 years with a partial absence of teeth. The patients were 28 men and 36 women. The reference group consisted of 56 people (27 men and 29 women) aged 21 to 66 years, who came to the dentist with limited minor defects in the dentition in the lower jaw (1-3 teeth) and who had no diseases of hard tissues and periodontal diseases at the time of the examination; they have satisfactory oral hygiene.

To be included in the clinical group, in accordance with the Clinical Recommendations of the Dental Association of Russia (Decree No. 15 of September 30, 2014), patients met the following criteria: the presence of permanent teeth, limited minor defects in the dentition in the lower jaw (1-3 teeth), lack of pathology of the temporomandibular joint, the absence of diseases of the oral mucosa, lack of dentition and malocclusion, the absence of pronounced periodontal pathology, and the absence of prostheses on implants before the age of 18 years. Exclusion criteria: the presence of somatic and mental illness, pregnant and lactating women and persons with removable orthopaedic structures and orthodontic appliances. All patients gave conscious informed consent to participate in the study in accordance with the current legislation of the Russian Federation.

Touareg spiral titanium implants manufactured by ADIN Dental Implant Systems Ltd and SPI implants made by AlphaBio Tec Ltd (both Israeli companies) were mounted in the area of defects on the lower jaw, 124 implants, for further manufacturing of fixed prostheses. The volume of bounded defects for dental prosthetic rehabilitation was one to two teeth strictly on one side, so that it was possible to assess objectively the consequences of a change in the dominant chewing side, in the event of this process.

Full-fledged osseointegration of implants was recorded by 2.5 to 3.0 months on the lower jaw, and by 5 to 6 months on the upper jaw from the moment of implantation, which was confirmed by resonance frequency analysis using Osstell Mentor implant stability meters. Implant stability quotient (ISQ) indicators made on average 57.7 [55.8 $\div 59.4]$ relative units in all patients, which testified to full osseointegration and high stabilization of implants. This was the basis for referring patients to the orthopaedic stage of treatment. The patients were examined before fixing the orthopaedic structure, in 3 to 6 and 9 to 12 months from the beginning of the study.

The osseointegration control methods included dental radiographic techniques-orthopantomography, focused dental radiography (Orthophos XG 3 DS apparatus; Sirona Dental Systems, Germany).

The results were evaluated separately by cortical plate (no change, thinning, and/or violation of its integrity) and osseous tissue around the implant (no change, horizontal, and/or vertical alveolar ridge resorption). The signs of cortical plate thinning and occurring trabecular bone porosity in the peri-implant zone were primarily considered as X-ray criteria for incomplete osseointegration and/or threat of osseointegration failure. ${ }^{33}$

These studies were supplemented by local densitometry. Visualization of brightness in shades of gray made it possible to obtain informative curves of changes in osseous tissue density in horizontal and vertical projections, as well as to determine the average osseous tissue density in individual parts of the jaw (-Fig. 1).

Finally, the distribution of the osseous tissue density was obtained in the vertical section, alveolar and deep intraosseous horizontal sections, in the gap between the tooth and the implant (two implants). When assessing the osseous tissue density values, the data obtained on the basis of the analysis of digital orthopantomograms using the SIDEXIS SIRONA radiovisiographic program, the

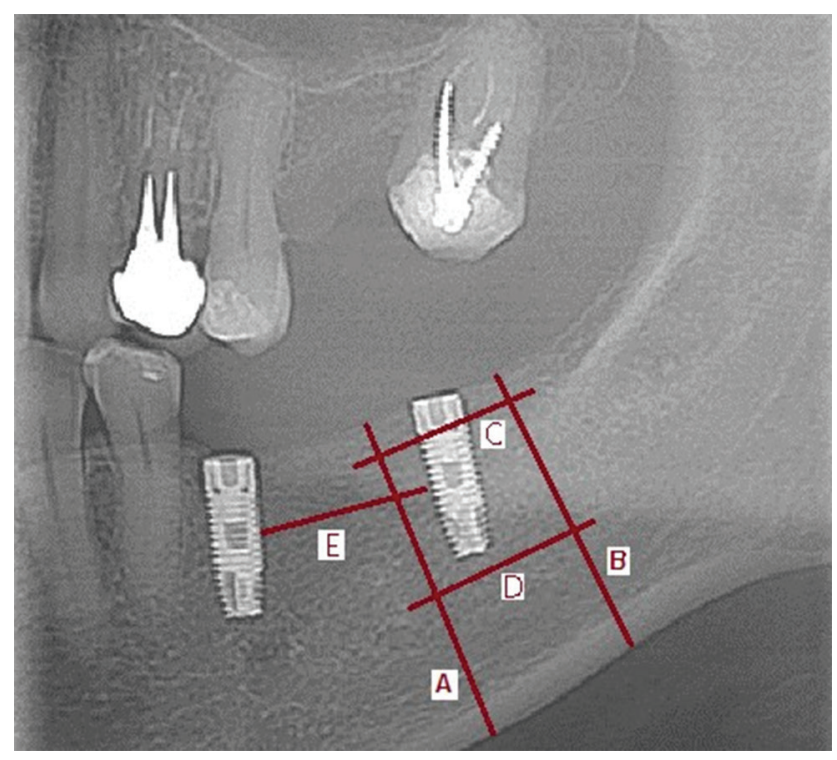

Fig. 1 The course of densitometric determination of osseous tissue density on orthopantomography and focused radiovisiographs. (A, B) Vertical sections: perpendicular from the cortical plate toward the alveolar ridge, in the projection of the interdental spaces and/or in the spaces between the teeth and implants. (C) Alveolar horizontal section: perpendicular to the previous ones at a distance of at least $2 \mathrm{~mm}$ (usually $2.5-3.0 \mathrm{~mm}$ ) from the buccal edge of the alveolar ridge, crossing the implant section. (D) Intraosseous horizontal section. Under the implant, at least $2 \mathrm{~mm}$ (usually $2.5-3.0 \mathrm{~mm}$ ) deeper than its tip, in parallel to the previous section. (E) Additional horizontal section: between the midpoint along the length of the implant and the similar point of the adjacent tooth root or implant (23, in our modification). 
Orthophos XG 3 DS apparatus software, were taken as approximate boundaries of the norm.

In particular cases, 3D computed tomography was used. The study was performed using a Hyperion X9 dental digital tomography (MyRay, France). The condition of the existing teeth, periapical tissues, osseous tissue, in particular, in the peri-implant region, was evaluated on the tomograms.

A chewing function was studied prior to the treatment beginning 3 to 6 and 6 to 12 months after the placement of intraosseous implant-supported fixed dentures. Before the beginning of treatment, a preferential (functionally dominant) side of chewing was established using a functional test, which, as expected, turned out to be with a predominance of the right side in a ratio of $\sim 2: 1$ with isolated cases of a mixed type, when it was impossible to determine the dominant chewing side. As known, the innervation of the maxillofacial region and limbs coincides on the side; hence, the dominant side of chewing coincides with the dominant human hand in $95 \%$ of cases, in the absence of local causes (e.g., dentin pathologies or partial loss of teeth). ${ }^{36}$

\section{Gnathodynamometry}

Normal biting forces-part of the force that is actually used by a person on individual teeth or parts of the jaw. It should be distributed evenly between all groups of teeth forming a dense fissure-tubercular contact. Chewing pressure was evaluated using gnathodynamometry (GDM) by means of the Vizir E-1000 apparatus (Elektropribor Central Research Institute, St. Petersburg, Russia). The functionally dominant side of chewing in this method was determined by the predominance of chewing forces. The study was performed on molars; the result was expressed in $\mathrm{N}$. This technique made it possible to objectively measure the efforts of the masticatory muscles to adequate loads on the tooth periodontal tissues under normal and pathological conditions of the dentition. ${ }^{35}$ Before each procedure, a presanitized elastic shock absorber was put on the sensor and it was proposed to squeeze the sensor between the first upper and lower molars of both sides of the jaw until there were unpleasant sensations in the periodontal of these teeth. The obtained values were entered in an individual card.

\section{Surface Interference Electromyography}

The study was performed using the NMA-4-01 Neuromin apparatus (Medicom MTD NKPF; Taganrog, Russia). After frequency-amplitude filtering, the absolute value of the maximum and average electromyography (EMG) amplitudes $(\mu \mathrm{V})$ and the force value $(\mu \mathrm{V} \cdot \mathrm{s})$ were calculated in accordance with the manufacturer's instructions. With surface EMG of the masticatory muscles, a high reproducibility of measurements was shown, and information was obtained on the preference of this technique in cases when it is necessary to study the general organization of the motor apparatus activity. ${ }^{37}$ The functionally dominant side of chewing in this method was determined by the predominance of amplitude indicators $(\mu \mathrm{V})$. Registration was performed by bipolar electrodes with a constant area and a fixed distance between them. Used rectangular electrodes with an area of $50 \mathrm{~m}^{2 . \mathrm{mm}}\left(10^{`} 5 \mathrm{~mm}\right)$, mounted on an insulating platform $40 / 20 \mathrm{~mm}$ with an interelectrode distance between the centers of the electrodes of $20 \mathrm{~mm}$. The bioelectric activity of the masticatory muscle ( $m$. Masseter) was recorded symmetrically on both sides. The insulating platform was located in the area of the motor point of the muscle, anatomically corresponding to the distribution area of the end plates of the terminal branches of the nerve, so that one recording electrode was directly above the motor point and the other was shifted toward the tendon, so that the longitudinal axis of the bipolar electrode was located along the muscle. The motor point was determined by palpation at the site of greatest muscle convexity at its maximum arbitrary contraction, as well as according to existing schemes for clinical use. During recording, the subjects sat without the support of the head and maintained its natural position. They were asked to grit their teeth with maximum force. Muscular activity was recorded for 5 seconds with the greatest possible compression of the teeth. The examinees were asked to squeeze as much as possible teeth in the position of maximum contact of the upper and lower teeth and maintain this level of tension throughout the recording period. Then the curve was recorded with muscle relaxation for 5 seconds. The indicated cycle was repeated 10 times. When recording the received signal, a digital high-pass filter of $2000 \mathrm{~Hz}$ and a low-pass filter of $3 \mathrm{~Hz}$ were used, the sweep speed was 50 milliseconds/d, and the sensitivity at rest was $50 \mu \mathrm{V} / \mathrm{d}$, with an arbitrary muscle contraction$500 \mu \mathrm{V} / \mathrm{d}$. EMG signals were stored in computer memory for subsequent analysis. The effectiveness of this method is described in the paper "Estimation of the functional state of the chewing link of the dental jaw system according to diagnosynametry and electromyography in persons 18-35 years with pregniture primo" Shemonaev Victor Ivanovich; Mashkov Alexander Vladimirovich; Maloletkova Anna Alekseevna; Badrak Evgeny Yuryevich; Klauchek Sergey Vsevolodovich, 2014.

Overall treatment outcomes and adaptation to implant-supported fixed structures were evaluated using two tests. Visual analogue scale (VAS) allowed for the assessment of the patient's subjective opinion about the treatment outcomes in dynamics, the result was expressed in $\mathrm{cm}$ when measuring a special scale on the questionnaire, ${ }^{38}$ values from 5.1 to $7.0 \mathrm{~cm}$ were interpreted as satisfactory, and those below $5.0 \mathrm{~cm}$ were considered unsatisfactory. The medical questionnaire Prognosis of Adaptation to Orthopedic Structures $^{39}$ was used as an objective method. According to this questionnaire, the dysadaptation coefficient (DAC) was calculated in points. Results above 10 are considered a sign of incomplete adaptation to orthopaedic structures. ${ }^{34}$

Statistical analysis was performed using the Statistica 10.0 software (StatSoft Inc., United States). Since the normal distribution hypothesis was rejected, nonparametric criteria were used: the distribution was expressed as the median and the interval between the first and third quartiles (Me $[\mathrm{Q} 1 \div \mathrm{Q} 3])$ and the Mann-Whitney U test $(p<0.01)$ to compare the samples. 


\section{Results}

After application and fixation of the intraosseous implant-supported fixed dentures, there was a change in the dominant side of chewing in 40 (62\%) patients (18 men and 22 women) within 3 to 6 months, which we regarded as a return to the status that existed before the formation of the bounded defects and without a change in the dominant side of chewing in 24 (38\%) patients ( 9 men and 14 women). Several such cases were explained by compromise changes in the nature of chewing due to the presence of defects in the dentition on the nonprosthetic side. These patients were referred to the first subgroup, while patients retaining the same dominant chewing side (usually the right side) as before treatment were referred to the second subgroup.

\section{The Radiological Study}

Radiographs taken prior to the beginning of the orthopaedic stage of treatment and at different periods of the use of fixed dentures showed the absence of signs of osteoresorption or other osseous tissue pathology in the implantation region in the vast majority of cases (90\% in the first clinical subgroup, and $95.8 \%$ in the second subgroup). The compact alveolar ridge plate was preserved; the state of osseous tissue around the implants indicated stable osseointegration.

After the patients began to use orthopaedic dental structures, some patients showed radiological signs of the osseous tissue pathology in the jaws in the peri-implant region; however, the frequency of their detection was insignificant (-Table 1). The number of cases found is representative enough to obtain these results and conclusions.

In the first clinical subgroup, changes in osseous tissue were recorded in 3 to 6 months of follow-up in one case, and in 9 to 12 months in three other cases. The total frequency of the detected changes was $10.0 \%$; they affected the cancellous bone, and in one case, the trabecular bone and the bone plate of the alveolar ridge. In the second clinical subgroup, changes were detected in only one patient in 9 to 12 months, and they affected the trabecular bone.

The revealed signs testified to the initial stages of osteoresorption and consisted of moderate atrophy of the alveolar ridge (less than a quarter of the implant length), thinning of the bone plate, and unilateral horizontal resorption of the osseous tissue around the implant. In the future, they could progress, and in this connection, they were regarded as peri-implantitis risk factors.

\section{Measurement of the Osseous Tissue Density}

Because of quantitative processing of X-ray densitograms, the data were obtained on the dynamics of the average osseous tissue density in the peri-implant region in patients of these clinical subgroups. They are presented in - Table 2.

The data obtained indicate that in patients of both clinical subgroups signs of full osseointegration of the implants persist by 9 to 12 months of observation; moreover, in the second group, a decrease in the thickness and density of the bone plate and the trabecular bone immediately under the implant is somewhat less intense than in the first clinical subgroup. This is probably associated with a more adequate distribution of loads on the implant due to the absence of a change in the dominant side of chewing.

Thus, according to the results of X-ray control, during the use of the intraosseous implant-supported fixed dentures, stable osseointegration remained for 12 months of observation. Cases of osseous tissue pathology did not exceed $10 \%$ in clinical subgroups; according to the results of the osseous tissue density determination, they could be attributed only to the initial manifestations of osteoresorption.

Quantitative data obtained from the examination of these patients using GDM and EMG are presented in - Fig. 2. In the experimental group, chewing pressure made on average 233.0 [223.8 $\div 240.5$ ] $\mathrm{N}$ on the dominant chewing side, and 196.7 [ $189.5 \div 204.4$ ] on the non dominant side.

In patients of the first clinical group, before the beginning of the orthopaedic stage of treatment, the values of this indicator were close to the following: in the first subgroup chewing pressure amounted to 227.3 [219.5 $\div 234.8] \mathrm{N}$, and in the second subgroup it was $225.3[215.0 \div 237.1] \mathrm{N}$ on the dominant side; on the nondominant side chewing pressure made 190.8 [183.9 $\div$ 196.6] and 197.8 [185.6 $\div$ 206.3] N, respectively. Differences between the groups were not significant during this observation period.

The period of 3 to 6 months from the beginning of the use of prostheses was accompanied by a significant increase in

Table 1 The frequency of detecting radiological signs of incomplete and/or delayed osseointegration in patients of the clinical group

\begin{tabular}{|l|l|l|l|}
\hline Indicator & Time limits & First subgroup & Second subgroup \\
\hline \multirow{5}{*}{ Bone plate } & Beginning & 0 & 0 \\
\cline { 2 - 4 } & $3-6$ months & 0 & 0 \\
\cline { 2 - 4 } & $9-12$ months & $1 / 40(2.5 \%)$ & 0 \\
\hline \multirow{5}{*}{ Trabecular bone } & Beginning & 0 & 0 \\
\cline { 2 - 4 } & $3-6$ months & $1 / 40(2.5 \%)$ & 0 \\
\cline { 2 - 4 } & $9-12$ months & $3 / 40(7.5 \%)$ & $1 / 24(4.2 \%)^{\mathrm{a}}$ \\
\hline \multirow{5}{*}{ Total deviations } & Beginning & 0 & 0 \\
\cline { 2 - 4 } & $3-6$ months & $1 / 40(2.5 \%)$ & 0 \\
\cline { 2 - 4 } & $9-12$ months & $4 / 40(10.0 \%)$ & $1 / 24(4.2 \%)^{\mathrm{a}}$ \\
\hline
\end{tabular}

aSignificant differences between the groups. 
Table 2 Average osseous tissue density in the dynamics of adaptation to intraosseous implant-supported fixed dentures (Me $[\mathrm{Q} 1 \div \mathrm{Q} 3]$ )

\begin{tabular}{|l|l|l|}
\hline Time limits & First subgroup & Second subgroup \\
\hline \multicolumn{3}{|c|}{ Tooth root-implant gap } \\
\hline Beginning & $0.39[0.30 \div 0.46]$ & $0.42[0.33 \div 0.51]$ \\
\hline $3-6$ months & $0.44[0.33 \div 0.50]$ & $0.47[0.38 \div 0.55]$ \\
\hline $9-12$ months & $0.45[0.34 \div 0.51]$ & $0.48[0.42 \div 0.58]$ \\
\hline Tissue under the implant \\
\hline Beginning & $0.42[0.33 \div 0.51]$ & $0.43[0.34 \div 0.53]$ \\
\hline $3-6$ months & $0.47[0.39 \div 0.56]$ & $0.51[0.43 \div 0.61]$ \\
\hline 9-12 months & $0.43[0.35 \div 0.54]$ & $0.46[0.37 \div 0.56]$ \\
\hline Compact plate \\
\hline Beginning & $0.65[0.59 \div 0.73]$ & $0.70[0.62 \div 0.75]$ \\
\hline $3-6$ months & $0.62[0.53 \div 0.68]$ & $0.67[0.57 \div 0.71]$ \\
\hline 9-12 months & $0.57[0.48 \div 0.64]$ & $0.62[0.50 \div 0.69]^{a}$ \\
\hline
\end{tabular}

${ }^{a} p<0.05$ between groups by the Mann-Whitney $\mathrm{U}$ criterion.
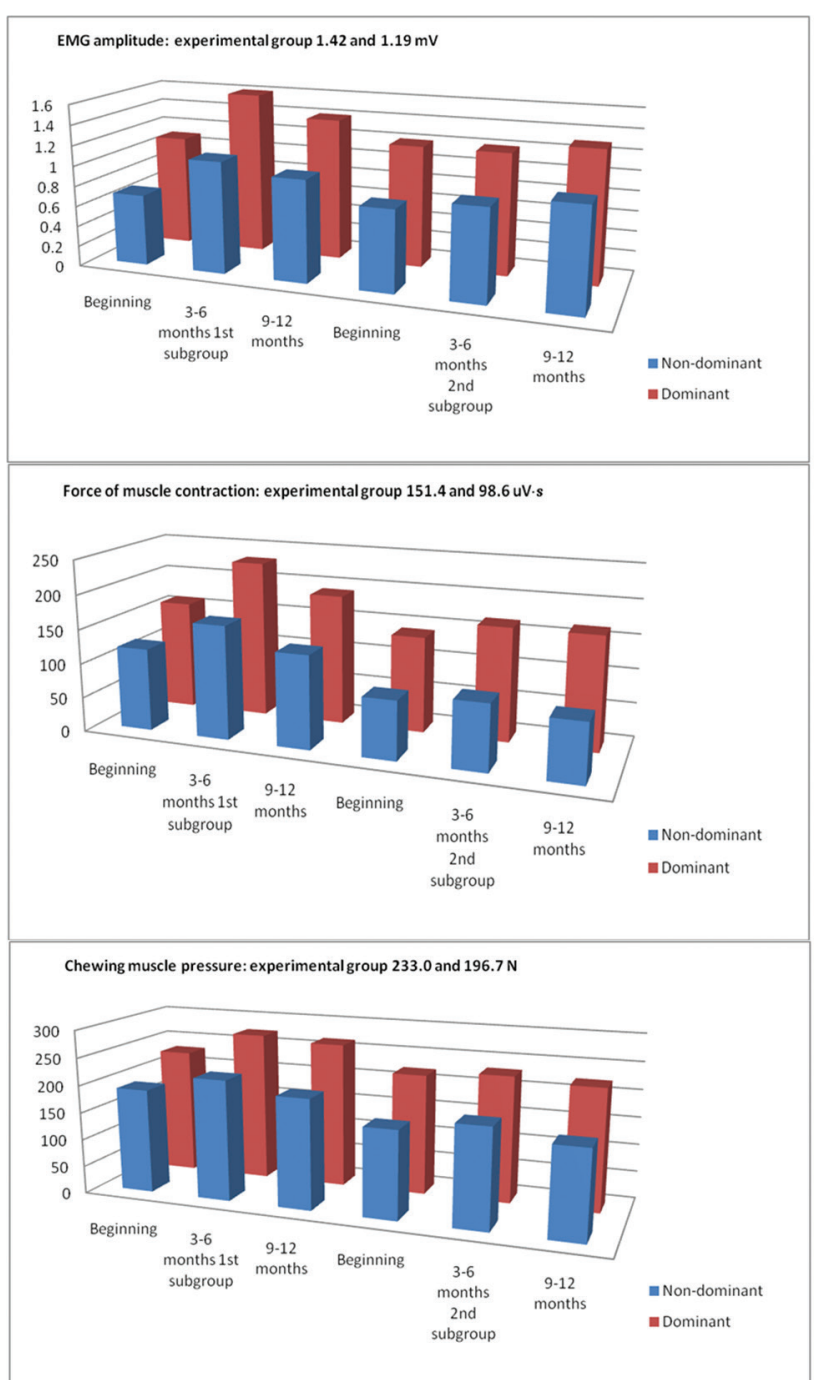

Fig. 2 Functional indicators of the chewing link of dentition. EMG, electromyography. chewing pressure up to 262.3 [249.2 $\div 273.7] \mathrm{N}$ on the dominant side (increase in $12.4 \%$ ) in the first subgroup, and to $225.2[215.0 \div 236.4] \mathrm{N}$ on the nondominant side (increase in $14.8 \%$ ). For the second subgroup, only a slight tendency to such a change was noted.

During 9 to 12 months of observation the increased value of the indicator remained in the first subgroup, reaching up to 255.7 [ $245.4 \div 264.9$ ] $\mathrm{N}$ on the dominant side; in the second subgroup, the indicator values were within the established biological norm on both sides. The EMG amplitude in the experimental group was $1.42[1.35 \div 1.49] \mathrm{mV}$ on the functionally dominant side and $1.19[1.12 \div 1.24] \mathrm{mV}$ on the nondominant side; the average muscle contraction force was $151.4[145.7 \div 157.6] \mu \mathrm{V}$ s and $98.6[93.6 \div 103.3] \mu \mathrm{V}$.s, respectively.

The data given in - Fig. 2 show that prior to start the orthopaedic treatment stage, patients of the clinical group demonstrated lower EMG amplitudes: $1.27[1.16 \div 1.36] \mathrm{mV}$ on the dominant side and $0.89[1.80 \div 0.97] \mathrm{mV}$ on the nondominant side. During the period of adaptation to dentures, the EMG amplitudes in this subgroup increased to 1.67 [1.54 $\div$ $1.79] \mathrm{mV}$ and $1.43[1.33 \div 1.51] \mathrm{mV}$, respectively. During time limits, they decreased slightly, but exceeded the values in the reference group by 7.0 and $10.0 \%$. For the second subgroup, this dependence was not observed, and at all periods of observation, the EMG amplitude values were close to those in the experimental group.

A similar picture was revealed in the analysis of the average EMG force. Before the beginning of the orthopaedic treatment stage, the numerical value of the indicator was 165.0 [153.2 $\div 175.9] \mu \mathrm{V}$.s on the dominant side in the first subgroup, and $122.6[112.0 \div 133.6] \mu \mathrm{V}$.s on the nondominant side; during 3 to 6 months this indicator was $236.6[122.5 \div 149.4] \mu \mathrm{V} \cdot \mathrm{s}$ and $175.1[162.8 \div 187.2] \mu \mathrm{V}$.s (an increase of more than in a third); during 9 to 12 months of observation it was $198.5[186.7 \div 210.1] \mu \mathrm{V}$.s and 140.8 [131.4 $\div 149.9] \mu \mathrm{V} \cdot \mathrm{s}$, respectively. In the second subgroup, the values of the average reduction force varied within 143.0 to $166.3 \mu \mathrm{V}$ s on the dominant side, and within 99.4 to $116.0 \mu \mathrm{V}$.s on the nondominant side. These differences were interpreted as signs of tension in the masticatory muscles and more intensive processes of adaptation to fixed orthopaedic structures in response to a change in the dominant side of chewing.

\section{Assessment of Overall Treatment Outcomes}

Treatment outcomes were determined in these subgroups of the first clinical group on the scales of subjective and objective assessment. These quantitative results are presented in - Table 3.

The presented data show that after application and fixation of the intraosseous implant-supported fixed dentures, the process of regaining the usual dominant chewing side is accompanied by a relative deterioration in the overall treatment results according to the subjective VAS and objective DAC rating scale.

During the period of adaptation to dentures (3-6 months from the start of operation), the VAS indicators decreased by $22.3 \%$ in patients of the first subgroup, while in patients 
Table 3 Indicators of adaptation to intraosseous implant-supported fixed dentures (Me [Q1\%Q3])

\begin{tabular}{|l|l|l|l|l|}
\hline \multirow{2}{*}{ Indicator } & \multirow{2}{*}{ Experimental group } & \multicolumn{3}{|c|}{ Clinical group } \\
\cline { 3 - 5 } & & Time limits & First subgroup & Second subgroup \\
\hline \multirow{2}{*}{ VAS, cm } & $9.6[9.2 \div 9.8]$ & Beginning & $7.2[6.7 \div 7.8]^{*}$ & $7.5[7.0 \div 8.1]^{*}$ \\
\cline { 3 - 5 } & & $3-6$ months & $5.6[5.2 \div 6.0]^{*}$ & $6.8[6.1 \div 7.6]^{*} \#$ \\
\cline { 3 - 5 } & & $9-12$ months & $8.0[7.4 \div 8.5]$ & $8.7[7.8 \div 9.1]$ \\
\hline DAC, un & - & $3-6$ months & $11.5[11.1 \div 11.8]$ & $5.2[4.8 \div 5.5] \#$ \\
\cline { 3 - 5 } & & $9-12$ months & $6.7[6.4 \div 6.9]$ & $4.4[4.0 \div 4.6] \#$ \\
\hline
\end{tabular}

Abbreviations: DAC, dysadaptation coefficient; VAS, visual analogue scale.

Note: ${ }^{*}$ and \# denote comparisons and significant differences.

of the second subgroup these values reduced only by $9.3 \%$ $(p<0.01)$. In the reference group, the average score was 9.6 throughout the study.

Small differences persisted by 9 to 12 months of follow-up. Similarly, in patients of the first subgroup, in 3 to 6 months after application and fixation of the intraosseous implant-supported fixed dentures DAC was 2.21 times higher than the value in the second subgroup ( $p<0.01)$. In 9 to 12 months, the DAC values differed by 1.53 times in the subgroups.

\section{Discussion}

Analyzing the obtained results, we proceeded from the notion that the indicators of the two chewing function research methods employed quite well reflect the specificity of adaptation to dentures and complement each other when used together. ${ }^{37}$

Using the finite element method, Alvarez-Arenal et $\mathrm{al}^{35}$ came to the conclusion that in terms of loads along the axis of the implant and abutment it is not recommended for repeated forces to exceed $150 \mathrm{~N}$, while for lateral and rotational loads even $40 \mathrm{~N}$ forces may be negative.

Furthermore, the picture in the oral cavity that we observe before prosthetics is connected in many respects with dynamic changes in the interocclusal ratios, which, by definition, themselves are not normal at the time of obtaining the occlusogram.

In their recent big review, Graves et $\mathrm{al}^{40}$ indicate that there is a debate about how much occlusion plays an important role in the subsequent implant stability and the peri-implantitis incidence. They conceive that these discussions are more likely determined by the extreme diversity of the implants and their design. Other things being equal, the closer to physiological norms the occlusal surfaces are formed, the lower the risk of developing late complications of dental implantation.

The emergence of the so-called solid free-form manufacturing technologies or rapid prototyping technologies gave the opportunity to manufacture specially designed products directly from a computer model with specific shapes and porosity.

In this case, the occlusal relief of the restored tooth is selected from the data bank and customized for a particular patient. At the same time, there are limitations due to the lack of long-term studies or clinical trials, especially in relation to the prediction of the life cycle of such prostheses. ${ }^{41}$

Anyway, Diment et $\mathrm{al}^{8}$ show in a large meta-analysis that out of 350 evidence-based clinical trials comparing the results of 3D printing for clinical purposes using routine technologies $58.3 \%$ of studies were in the oral and maxillofacial surgery field, which included dentistry and orthopaedic surgery of the jaw, face and skull, and those covering the musculoskeletal system (23.7\%) made up the second group. It was concluded that the 3D-printed devices outperformed their conventional comparators. At the same time, it is clear that more rigorous and long-term assessments are needed to determine if 3D-printed devices are clinically relevant before they become part of standard clinical practice.

Studies of 804 patients at the Osaka Dental University, divided into the pre- and postimplantation groups and subgroups depending on the number of remaining dental supports according to the Eichner classification, showed that the subjective assessment of the treatment expectations and outcomes is very variable and multifaceted. The participants were tested using the general questionnaire-the General Oral Health Assessment Index and the oral health-related quality of life questionnaire. Whereas before the beginning of treatment, the total score on the questionnaire significantly depended on the volume of the forthcoming prosthetics, after the treatment is completed, there was practically no dependence. The authors once again emphasize that in assessing the results of orthopaedic treatment in dentistry, much depends on the subjective expectations of the patient. ${ }^{20}$

The treatment satisfaction questionnaire was specifically developed to evaluate the importance of age, gender, readiness for improved oral hygiene, specific treatment duration, and implantation volume. In total, 182 patients underwent the survey, and the duration of the use of prostheses reached on average 2.5 to 5.0 years. A significant relationship was found between the comfort indicator and previous informing the patient about the nature and features of the upcoming treatment, between the general experience of treatment with dentists and the conscious decision to choose dental implantation as a method of such treatment. The obtained results emphasize the need to transmit logical, truthful information to patients when considering the upcoming treatment using dental implantation. The most informed patient will have realistic 
expectations, which are realized finally in a high degree of satisfaction. ${ }^{25}$

Our study has shown that adaptation to fixed dentures is accompanied by a period of relatively high and unusual loads on the mounted dentures owing to increased functional activity of the masticatory muscles. As a result, within 3 to 6 months' period of adaptation to intraosseous implant-supported nonfixed dentures, almost two-thirds of patients returned to the usual functionally dominant side of chewing. This process, as the results of our study showed, is accompanied by a temporary decrease in satisfaction with the treatment outcomes, both from the point of view of the dentist and the patient. This, in particular, is associated with a period of relatively high and unusual loads on the mounted dentures because of the increased functional activity of the masticatory muscles. Uncontrolled loads on the intraosseous implant-supported dentures can provoke microtraumas, infection penetration into the osseointegration zone and contribute to its violation due to the development of secondary complications up to the loss of implants.

\section{Conclusions}

The period of 3 to 6 months from the date of placing the intraosseous implant-supported fixed dentures is characterized by frequent changes in the dominant chewing side, relatively unstable chewing function indicators with a predominance of increased load on the chewing muscles and mounted dentures. Relatively low indicators are typical of these patients according to the subjective VAS rating scale and objective medical questionnaire with the calculation of DAC.

The above facts indicate that the change in the dominant side of chewing is a serious factor affecting the patient's adaptation to implant-supported fixed structures, and it is expedient to consider these factors when planning an individual patient adaptation complex for dental orthopaedic structures.

\section{Conflict of Interest}

None declared.

\section{References}

1 Fernandez-Estevan L, Selva-Otaolaurruchi EJ, Montero J, Sola-Ruiz F. Oral health-related quality of life of implant-supported overdentures versus conventional complete prostheses: retrospective study of a cohort of edentulous patients. Med Oral Patol Oral Cir Bucal 2015;20(4):e450-e458

2 Müller F, Duvernay E, Loup A, Vazquez L, Herrmann FR, Schimmel M. Implant-supported mandibular overdentures in very old adults: a randomized controlled trial. J Dent Res 2013;92(12, Suppl):154S-160S

3 Raikar S, Talukdar P, Kumari S, Panda SK, Oommen VM, Prasad A. Factors affecting the survival rate of dental implants: a retrospective study. J Int Soc Prev Community Dent 2017;7(6):351-355
4 Bassi F, Carr AB, Chang TL, et al. Clinical outcomes measures for assessment of longevity in the dental implant literature: ORONet approach. Int J Prosthodont 2013;26(4):323-330

5 Moraschini V, Poubel LA, Ferreira VF, Barboza EdosS. Evaluation of survival and success rates of dental implants reported in longitudinal studies with a follow-up period of at least 10 years: a systematic review. Int J Oral Maxillofac Surg 2015;44(3):377-388

6 Zanetti EM, Pascoletti G, Calì M, Bignardi C, Franceschini G. Clinical assessment of dental implant stability during follow-up: what is actually measured, and perspectives. Biosensors (Basel) 2018;8(3):e68

7 Jang HW, Kang JK, Lee K, Lee YS, Park PK. A retrospective study on related factors affecting the survival rate of dental implants. J Adv Prosthodont 2011;3(4):204-215

8 Toutios A, Ouni S, Laprie Y. Estimating the control parameters of an articulatory model from electromagnetic articulograph data. J Acoust Soc Am 2011;129(5):3245-3257

9 Damiati L, Eales MG, Nobbs AH, et al. Impact of surface topography and coating on osteogenesis and bacterial attachment on titanium implants. J Tissue Eng 2018;9:2041731418790694

10 Greenberg AM. Advanced dental implant placement techniques. J Istanb Univ Fac Dent 2017;51(3, Suppl 1) :S76-S89

11 Córdoba A, Manzanaro-Moreno N, Colom C, et al. Quercitrin nanocoated implant surfaces reduce osteoclast activity in vitro and in vivo. Int J Mol Sci 2018;19(11):e3319

12 Menezes HH, Naves MM, Costa HL, et al. Effect of surgical installation of dental implants on surface topography and its influence on osteoblast proliferation. Int J Dent 2018;2018:4089274

13 Novochadov VV, Krylova AS, Anikeev NA, et al. The functionalizing bioactive surface of screw titanium implants with chitosan: fabrication and surface features. Eur. J. Mol. Biotech 2016;4(4):139-147

14 Wang J, Meng F, Song W, et al. Nanostructured titanium regulates osseointegration via influencing macrophage polarization in the osteogenic environment. Int J Nanomedicine 2018;13:4029-4043

15 Sirak SV, Sletov AA, Gandylyan KS, Dagueva MV. Direct dental implantation in patients with included dentition defects. Medical News of the North Caucasus 2011;21(1):51-54

16 Teles FR, Teles RP, Uzel NG, et al. Early microbial succession in redeveloping dental biofilms in periodontal health and disease. J Periodontal Res 2012;47(1):95-104

17 Zekiy AO. Salivary markers of inflammation and osteoresorption to evaluate dental implant adaptation. J. Volgograd State Med. Univ 2015;4:63-66

18 Thoma DS, Brandenberg F, Fehmer V, Büchi DL, Hämmerle $\mathrm{CH}$, Sailer I. Randomized controlled clinical trial of all-ceramic single tooth implant reconstructions using modified zirconia abutments: radiographic and prosthetic results at 1 year of loading. Clin Implant Dent Relat Res 2016;18(3):462-472

19 Tonetti M, Palmer R; Working Group 2 of the VIII European Workshop on Periodontology. Clinical research in implant dentistry: study design, reporting and outcome measurements: consensus report of Working Group 2 of the VIII European Workshop on Periodontology. J Clin Periodontol 2012;39(Suppl 12):73-80

20 Albrektsson T, Canullo L, Cochran D, De Bruyn H. "Periimplantitis": a complication of a foreign body or a manmade "disease". Facts and fiction. Clin Implant Dent Relat Res 2016;18(4):840-849

21 Hong DGK, Oh J-H. Recent advances in dental implants. Maxillofac Plast Reconstr Surg 2017;39(1):33 
22 Elias CN, Rocha FA, Nascimento AL, Coelho PG. Influence of implant shape, surface morphology, surgical technique and bone quality on the primary stability of dental implants. J Mech Behav Biomed Mater 2012;16:169-180

23 Kandasamy B, Samson EP, Yaqoob A, Pandey P, Deenadayalan S, Das I. Evaluation of clinical parameters in implant maintenance phase for prevention of peri-implantitis. J Int Soc Prev Community Dent 2018;8(4):361-364

24 Isabel CA, Moysés MR, van der Bilt A, Gameiro GH, Ribeiro JC, Pereira LJ. The relationship between masticatory and swallowing behaviors and body weight. Physiol Behav 2015; 151:314-319

25 McCrea SJJ. An analysis of patient perceptions and expectations to dental implants: is there a significant effect on longterm satisfaction levels? Int J Dent 2017;2017:8230618

26 Eberhard L, Braun S, Wirth A, Schindler HJ, Hellmann D, Giannakopoulos NN. The effect of experimental balancing interferences on masticatory performance. J Oral Rehabil 2014;41(5):346-352

27 Ahlers MO, Bernhardt O, Jakstat HA, et al. Motion analysis of the mandible: concept for standardized evaluation of computer-assisted recording of condylar movements. Zeitschrift für Kraniomandibuläre Funktion 2014;6:333-352

28 Fuentes R, Arias A, Lezcano MF, Saravia D, Kuramochi G, Dias FJ. Systematic standardized and individualized assessment of masticatory cycles using electromagnetic 3D articulography and computer scripts. BioMed Res Int 2017;2017:7134389

29 Diment LE, Thompson MS, Bergmann JHM. Clinical efficacy and effectiveness of 3D printing: a systematic review. BMJ Open 2017;7(12):e016891

30 Dolgalev AA, Goman MV, Zaborovets IA. Assessment of patient adaptation to implant-supported dentures from the results of electromyographic studies. Russian J Dentistry 2010; $\mathrm{x}(5): 18-20$

31 Shah FK, Gebreel A, Elshokouki AH, Habib AA, Porwal A. Comparison of immediate complete denture, tooth and implant-supported overdenture on vertical dimension and muscle activity. J Adv Prosthodont 2012;4(2):61-71

32 Kybkalo AP, Sarkisov KA, Veysgeym LD, Pchelin IYu. Preferential side of chewing, chronical occlusion and cuspid guidance are additional constituents of functional occlusion. Russian Journal of Dentistry 2015;19(2):12-14

33 Lohmann $\mathrm{CH}$, Rampal S, Lohrengel M, Singh G. Imaging in peri-prosthetic assessment: an orthopaedic perspective. EFORT Open Rev 2017;2(5):117-125

34 Alvarez-Arenal A, Gonzalez-Gonzalez I, deLlanos-Lanchares H. Martin-Fernandez E, Brizuela-Velasco A, Ellacuria-Echebarria J. Effect of implant- and occlusal load location on stress distribution in locator attachments of mandibular overdenture. A finite element study. J Adv Prosthodont 2017;9(5):371-380

35 Nickel J, Spilker R, Iwasaki L, et al. Static and dynamic mechanics of the TMJ: plowing forces, joint load, and tissue stress. Orthod Craniofac Res 2009;12(3):159-167

36 van der Bilt A. Assessment of mastication with implications for oral rehabilitation: a review. J Oral Rehabil 2011;38(10):754-780

37 Durso FT, Geldbach KM, Corballis P. Detecting confusion using facial electromyography. Hum Factors 2012;54(1):60-69

38 Kanehira Y, Arai K, Kanehira T, Nagahisa K, Baba S. Oral health-related quality of life in patients with implant treatment. J Adv Prosthodont 2017;9(6):476-481

39 Shemonaev VI, Klauchek SV, Maloletkova AA, Shemonaev AV. The method of determining adaptation to orthopedic dental structures. RUS Patent 2441590. 2012

40 Graves CV, Harrel SK, Rossmann JA, et al. The role of occlusion in the dental implant and periimplant condition: a review. Open Dent J 2016;10:594-601

41 Kubilius M, Kubilius R, Varinauskas V, Žalinkevičius R, Tözüm TF, Juodžbalys G. Descriptive study of mandibular canal visibility: morphometric and densitometric analysis for digital panoramic radiographs. Dentomaxillofac Radiol 2016; 45(7):20160079 